\title{
Teaching medical students on the ethical dimensions of human rights: meeting the challenge in South Africa
}

Leslie London and G McCarthy University of Cape Town, Rondebosch and Department of Health, Bellville, South Africa, respectively

\section{Abstract}

Setting-Previous health policies in South Africa neglected the teaching of ethics and human rights to health professionals. In April 1995, a pilot course was run at the University of Cape Town in which the ethical dimensions of human rights issues in South Africa were explored.

Objectives-To compare knowledge and attitudes of participating students with a group of control students.

Design-Retrospective cohort study Subjects-Seventeen fourth-year medical students who participated in the course and 13 control students from the same class, matched for gender. Interventions-Students participated in a one-week module on ethics and human rights. Five months after the course had been run, students completed a semi-structured questionnaire exploring their knowledge and attitudes with regards to ethics and human rights issues.

Main outcome measures-Knowledge scores, attitude scores and various individual indicators of attitude.

Results-Clear benefits for overall knowledge score, for four out of five individual knowledge questions and for one of the attitude questions, were demonstrated. Participating students also appeared to be more convinced of the need for teaching on the ethical dimensions of human rights at postgraduate level and that such teaching should also be integrated in the curriculum. The low response rate amongst controls may have selected students who were more socially conscious, thereby leading to an underestimate of the true impact of the course. Conclusion-The evaluation indicates clear benefits of the course for undergraduate students, and supports arguments for the inclusion of such courses in the training of health professionals. This is particularly important given the challenges posed by the Truth and Reconciliation Commission to the health professions to address past complicity in human rights abuses through reorientation of medical training in South Africa.

(Fournal of Medical Ethics 1998;24:257-262)

Keywords: Ethics; human rights; training; South Africa

\section{Introduction}

Training in medical ethics and human rights has been identified internationally as one of the key strategies for the prevention of torture and other human rights abuses. ${ }^{1-4}$ In South Africa, calls have previously been made for the medical profession to be pro-active in developing teaching initiatives in medical ethics for both undergraduates and postgraduates, ${ }^{5}$ particularly in light of the shameful record of medical complicity in apartheid abuses of political detainees. ${ }^{6}$ However, such calls went largely unheeded until relatively recently. With the political events that brought democracy to the country and a national commitment to developing a human rights culture, greater opportunities have arisen to place human rights and medical ethics on the agenda of institutions training health professionals.

Moreover, in June 1997 the South African Truth and Reconciliation Commission focused an entire two days of hearings on an examination of the role of the health sector in human rights abuses under apartheid. ${ }^{8}$ The hearings coincided with growing concern that the medical profession needs to re-examine its past failures in protecting the rights of apartheid's victims, and in maintaining ethical standards under apartheid. ${ }^{9-10}$ Central to many of the recommendations contained in submissions to the hearing was the urgent need to improve the ethical and human rights orientation of undergraduate and postgraduate training in the health professions.

One example of such an initiative, introduced as an elective option for students wishing to broaden their training experience, was a course run for medical students in their fourth year of training at 
the University of Cape Town (UCT) in 1995. This course was amongst the first in South Africa to address the ethical responsibilities of doctors in relation to prisoners and other vulnerable groups in institutional care ${ }^{11}{ }^{12}$ and is summarised below. The course was seen by many ${ }^{71314}$ as the first step towards re-establishing a human rights ethic in the training of medical professionals. This paper reports on an evaluation of the course conducted five months after completion to assess the impact of the course on the knowledge and attitudes of participating medical students.

\section{Course content and format}

Seventeen medical students volunteered to participate in the course which ran over five days in April 1995. The course was aimed at providing students with an appreciation of the circumstances under which human rights violations could occur, and the role that health professionals can play in combating these abuses. The course covered both international perspectives on medical complicity and local case studies and settings where human rights violations have occurred and continue to occur. Central to the course was the attempt to place the ethical responsibilities of medical professionals in the context of working in situations where human rights abuses occur.

Teaching methods included panel discussions, field visits to total institutions (a police station cell, a prison and a psychiatric facility) and intensive group work. Participants on a number of the panels included health professionals who were themselves torture survivors from political imprisonment and students were presented with role models very different from traditional medical student training. For example, it was important for students to meet and speak with doctors who, under the severely repressive circumstances of apartheid, took principled ethical stands in defence of human rights (often at some cost to themselves).

Because the course relied heavily on learning from the first-hand accounts and experiences of torture survivors, time was structured for debriefing during the course to deal with the expected emotional intensity generated by the material. Group work, informed by interviews, video material and probing case studies from clinical practice, were used to enable students to grapple with difficult ethical dilemmas. More detail on the course is available elsewhere. ${ }^{15}$

\section{Methods}

The evaluation used a retrospective cohort design. The study population included all medical students in their fourth year of training who were

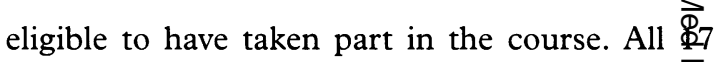
students who participated in the course we included in the study, as well as 34 contric students, matched for gender and randomly chiosen from the class listing of fourth year studen Students were notified by letter and invited $\Phi_{0}$ attend a lunchtime meeting where they would ${ }_{\text {Ee }}$ asked to participate in an evaluation of the cours. As enticements to attend, students were informed that lunch would be provided and video footage 3 the course would be shown. .

At the session, students were asked to complete a semi-structured questionnaire that containged four questions on demographics and past learnifg experiences, five questions on knowledge, and nine questions on attitudes towards ethical dimensions of human rights in medicine (table 7 . A score was constructed for knowledge based on post-coding of responses (maximum score 10). 0

For attitude, a range of questions was used. One question contained a series of statements probigg the relative importance of different competencs using a scale of one to five. For each individural competency, an a priori assumption was made as to whether these competencies were important for the objectives of the course. Desirable compegencies were scored positively while irrelevant compertencies were scored in the inverse direction. Ir the two sets of competencies included in the questio are listed in table 2.

Another two sets of questions probed the perceived professional responsibilities of a prisển medical officer and that of a hospital doctor towards a prisoner patient. The ideal score either question was ten. In addition to comparisèn of actual scores, the correlation (Pearson $\frac{3}{8}$ ) between scores for the two sets of questions wias calculated and compared between participatizg students and controls. This was done to test the hypothesis that students should see little difference in the responsibilities of doctors, irrespectie of whether they were hospital or prison mediogl officers.

Two further questions explored attitudes how teaching on the ethical dimensions of humin rights should fit into medical training, and w६be scored on a scale of one to five. The remainifigg questions on attitude included open-ended questions on condom usage in prisons, and on the sitidents' response to evidence of torture amongst prisoners, as well as a question probing studenty' responses to a clinical case scenario involving vilence against a farm worker (scaled from one $\overrightarrow{8}$ o five).

Post-coding of responses to the open-endsid questions for attitude (two out of eight questions) and knowledge (all five questions) was performed 
Table 1 Measurement of knowledge and attitude towards ethical dimensions of human rights amongst medical students questionnaire format

Demographics

Age

Gender

Past learning experiences

Attendance at course

Informed about course

Other teaching

Knowledge

Objective of Tokyo Declaration

Protection afforded by the Interim Constitution

How Steve Biko ${ }^{\star}$ died

Unethical practices by Biko doctors

The role of the Medical Association of South Africa (MASA)

Attitude

Important competencies

Professional responsibilities

Place in medical training

Condom usage in prisons

District surgeon confronted with evidence of torture

Response to farm worker assault

\author{
1 question closed ended \\ 1 question closed ended \\ 1 question closed ended \\ 1 question closed ended \\ 1 question closed ended \\ 1 question open ended \\ 1 question open ended \\ 1 question open ended \\ 1 question open ended \\ 1 question open ended \\ 1 question with 9 statements scaled 1 to 5 \\ 2 questions with 10 statements each (yes/no) \\ 1 question close ended 1 question scaled 1 to 5 \\ 1 question open ended \\ 1 question open ended \\ 1 question with 6 statements scaled 1 to 5
}

*Steve Biko was a political activist who was detained under South African security legislation and who died in police custody in 1978 as a result of torture. Evidence at the subsequent inquest illustrated how the doctors responsible for treating him subjugated his interests to those of the security police and neglected their ethical responsibilities as medical practitioners. A national and international outcry greeted attempts to exonerate these doctors and to cover up his maltreatment (see for example, reference 6).

${ }^{\star \star}$ A district surgeon was a state-appointed doctor charged with medico-legal responsibilities, including health care for prisoners and detainees.

independently by two observers (GM, LL) according to an a priori coding system. Both observers were blinded to whether the respondents were course participants or controls. This was done to minimise systematic observer error, which might be substantial in the coding of responses to openended questions. Inter-observer variation was assessed by comparing the agreement of the two blinded observers (GM and LL) in their scoring assessments. Kappa statistics which measure agreement for categorical data ${ }^{16}$ and Pearson's Correlation coefficients for continuous data ${ }^{17}$ were calculated. Kappa values ranged from 0.5 to 0.93 (good to excellent agreement) and Pearson's correlation coefficient from 0.45 to 0.82 (moderate to good agreement). Because of evidence of good overall agreement, data presented in the rest of

Table 2 Attitude measures - a priori assessment of importance

Important competencies

Understand psychosocial problems experienced by exiles

Knowing the functions of the public protector

Knowing where to get access to ethical declarations

Knowing the contents of ethical declarations

Counsel torture survivors

Know laws protecting prisoners' health care

$\star$ PTSD $=$ Post Traumatic Stress Disorder

\#The Public Protector is a statutory office dedicated to protecting the rights and dignity of South Africans receiving any public service. this paper is therefore based on results from one observer (LL).

All students were asked for verbal consent before participating in the evaluation which was anonymous and it was made explicitly clear that there was no relationship to their academic assessments.

\section{Results}

Of the 51 subjects selected, 30 participated in the assessment. These included all 17 who did the course $(100 \%$ response rate) and 13 out of 34 controls $(38.2 \%$ response rate). There were no significant differences $(p<0.05)$ between course participants and controls for age (means 22.3 and 22.4 years, respectively) or gender $(47 \%$ and $39 \%$ female, respectively).

Other teaching on ethics since the course was reported by 27 students, mostly in the form of lectures $(n=25)$, bedside $(n=2)$ and other $(n=3)$ teaching. It was apparent that five students $(17 \%)$ did not report that the class had received whole-class lectures on ethics, and appeared not to have remembered or attended these lectures.

Knowledge scores for the two groups of students are presented in table 3. It was clear that students who attended the course exhibited substantially better knowledge (about twice as good as the others), and this difference was statistically significant for four out of five individual questions and for the overall score.

Attitude measures are summarised in table 4 . None of the measures of attitude were significantly different between the two groups. 
Table 3 Mean knowledge scores (GM)

\begin{tabular}{|c|c|c|c|}
\hline & Cases & Controls & Significance \\
\hline Tokyo declaration & 1.35 & 0.31 & $\mathrm{p}<0.001$ \\
\hline Constitution & 0.82 & 0.62 & ns \\
\hline Unethical practices by Biko doctors & 1.77 & 1.08 & $\mathrm{p}=0.03$ \\
\hline Circumstances of Biko's death & 1.53 & 0.92 & $\mathrm{p}=0.005$ \\
\hline MASA activities & 1.41 & 0.31 & $\mathrm{p}=0.003$ \\
\hline Total knowledge score & 6.88 & 3.23 & $\mathrm{p}<0.001$ \\
\hline
\end{tabular}

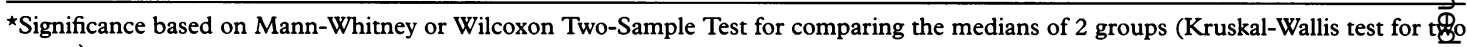
groups).

Table 4 Attitude measures

\begin{tabular}{|c|c|c|c|c|}
\hline & Cases & Controls & Significance & $\bar{c}$ \\
\hline Condom usage in prison & 2.35 & 2.00 & ns & \\
\hline Range of responsibility: & & & & \\
\hline prison doctor & 7.59 & 7.62 & ns & \\
\hline hospital doctor & 6.12 & 5.46 & ns & \\
\hline correlation for prison and hospital (Pearson's r; 95\% CI) & $0.82(0.57-0.93)$ & $0.22-0.37-0.69)$ & ns & \\
\hline Importance of: & & & & \\
\hline distinguishing PTSD & 3.77 & 3.77 & ns & \\
\hline understand exiles & 3.35 & 2.92 & ns & 도 \\
\hline counsel torture survivors & 4.00 & 3.39 & ns & \\
\hline history of BCM & 2.88 & 2.92 & ns & \\
\hline laws for prisoner health care & 4.06 & 4.08 & ns & \\
\hline name public protector & 3.29 & 3.08 & ns & 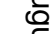 \\
\hline $\begin{array}{l}\text { functions public protector } \\
\text { ethics declarations }\end{array}$ & 3.82 & 3.85 & ns & क \\
\hline $\begin{array}{l}\text { ethics deciarations } \\
\text { - contents }\end{array}$ & 4.65 & 4.62 & ns & \\
\hline - access & 4.77 & 4.46 & ns & \\
\hline Summed score for above & 5.18 & 5.00 & ns & \\
\hline
\end{tabular}

*Significance based on Mann-Whitney or Wilcoxon Two-sample Test for comparing the medians of 2 groups (Kruskal-Wallis test f groups).

Table 5 Attitude to how teaching on ethical dimensions of human rights should take place

\begin{tabular}{|c|c|c|c|}
\hline & Cases & Controls & $\begin{array}{l}\text { Whole } \\
\text { sample }\end{array}$ \\
\hline In undergraduate teaching (\%) & 100 & 92.3 & 96.7 \\
\hline In postgraduate teaching $(\%)^{\star}$ & 82.4 & 15.4 & 53.3 \\
\hline In extra-curricular teaching (\%) & 41.2 & 53.8 & 46.7 \\
\hline $\begin{array}{l}\text { Mean scores: How strongly should } \\
\text { material be taught to }\end{array}$ & & & \\
\hline undergraduates? (Scale 1 to 5 ) & 4.12 & 4.31 & ns \\
\hline $\begin{array}{l}\text { Mean scores: How strongly should } \\
\text { ethics be an elective? (scale } 1 \text { to } 5 \text { ) }\end{array}$ & 1.94 & 2.33 & ns \\
\hline
\end{tabular}

${ }_{\star} \mathrm{p}<0.001$ based on Chi-squared test for difference in proportions.

Students were asked how they thought teaching on the ethical dimensions related to human rights should take place. The responses are summarised in table 5.

Both groups rated the place of teaching highly in the undergraduate curriculum and all but one student felt that ethical dimensions related to human rights should be taught at undergraduate level. However, students who attended the course were significantly more likely to report thinking that such teaching should also take place at postgraduate level $(\mathrm{OR}=25.7 ; 95 \%$ CI 2.81-334.2). Students who did the course were also more likely to feel that this teaching should be integrated rather than elective, although this difference wळs not statistically significant.

In the distribution of responses to the case sc $\vec{E}-$ nario involving assault of a farm worker, the

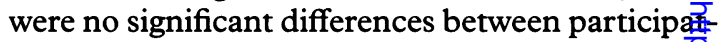
ing students and controls. However, in openended responses to the question probing the response to evidence of torture a clear differenge was seen. Students who attended the course were likely to score higher on this question than thoge who did not attend (participants' mean score 4. g4 $\mathrm{v}$ controls' 3.23; $\mathrm{p}<0.01$; Wilcoxon test).

Of those who did not attend the course, on two students reported that they had be informed in detail about the course by the participating class colleagues. Because this may have confounded the results, a sensitivity analysts was repeated with these two students included of the "participating students" group. However, thess did not substantially change the above findings (data available on request from authors).

\section{Discussion}

Five months after the course, participant studer appeared to have better knowledge scores, as w as identifying the importance of postgraduate training more frequently than "controls". They also were able to score better on one of the 
attitude indicators (district surgeon faced with evidence of torture). These findings tend to support findings of an immediate evaluation that the course had been relatively effective. ${ }^{18}$ The fact that participating students identified the importance of postgraduate teaching (table 5) further augurs well for the impact of the course on the students' lifelong learning commitment to ethical issues related to human rights. It also complements the needs identified by the students for training in prison medicine in earlier qualitative evaluations. ${ }^{19}$

Notwithstanding the positive findings, it was also evident from the study that overall indicators of attitude did not show substantial difference between the two groups. This might have two explanations: firstly, the attitude questions may have been too insensitive to detect any real differences. This was illustrated in the responses to the question around condom usage in prison, where both participating students and controls showed fairly insightful attitudes to the problem. Quantitative estimation of attitude, as is often done with studies of knowledge, attitude and practices (known as KAP surveys) are notoriously problematic in capturing meaningful data. ${ }^{20}$

\section{Selection bias}

However, a more likely problem was that there was a selection bias inherent in that control students who participated in the study were likely to be the more socially conscious students amongst the class. Non-response amongst control students was high (over $60 \%$ ) but our experience as teachers suggests that those students who did not attend the evaluation were less likely to have an interest in ethical aspects related to human rights. The bias introduced would therefore tend to underestimate the effect of the course. We plan to repeat the study on a non-contemporaneous control group in the future with better response rates to see if their results are indeed poorer than the controls, which would provide evidence to support the above supposition.

It was also interesting to note that the majority of both groups of students appeared to favour the integration of such teaching in the curriculum rather than its retention as an elective (median scores of both groups $<2.5$ ). Students who did the course were more likely to feel that teaching on the ethical dimensions of human rights should be integrated, although this difference was not statistically significant. Teaching on ethical issues related to human rights abuses have generally been sporadic and poorly integrated in medical curricula in South Africa to date. To our knowledge, only one other institution runs a com- plete course in ethical and medico-legal issues for undergraduates. The findings from this pilot suggest that it would be desirable to integrate such initiatives in the medical curriculum and are echoed in many of the submissions made to the TRC health sector hearings. ${ }^{22}$ Such courses, if they are to be taken seriously by all students, would need to be examinable for credit.

\section{Some qualifications}

Some qualifications to the findings may need to be made. For example, the scenario involving a district surgeon faced with evidence of torture may have effectively been measuring knowledge rather than attitude, since the case scenario was very similar to the experience of Dr Wendy Orr, who spoke to the students on the course, and whose actions ${ }^{822}$ were therefore well known to participants. (Dr Orr was a district surgeon responsible for the health care of prisoners and detainees during a period of severe political repression in South Africa in 1985. Because of clear evidence of sytematic torture of detainees and the failure of her medical superiors to act on this evidence, she brought a court order to restrain police from assaulting detainees in the area. See, for example, references 6 and 17.) Another case study may not have been scored as well by the participating students.

Secondly, the groups were small and the failure to show differences may be due to small sample size. In fact, in attitude assessment, many of the scores were in the expected direction but the differences were too small for statistical significance. This suggests the study underestimated the effectiveness of changes in attitude. However, given the small sample and the difficulties posed by subdividing the cohort according to demographic, religious or cultural variables that may influence knowledge and attitude, the generalisability of study is somewhat limited and care should be taken in inferring too much certainty from the results.

A weakness of this study lies in its design. Ideally, a trial of any intervention, including educational ones, should involve baseline estimation, have randomisation, and have sufficient study participants to achieve sufficient power to meet the study objectives. Moreover, the period of follow-up should be sufficient to assess whether there has been long term benefit. However, given the practical situation of evaluating a new course, where neither randomisation nor blinding of subjects was feasible, the study design chosen was the best option for evaluation. Attempts to follow up the participating students in the long term will be 
made to assess what long term impact the course has on their practices beyond the medical school.

\section{Conclusion}

Despite its limitations which appear largely to lead to underestimation rather than overestimation of effect, this evaluation appears to demonstrate a significant impact of the course. There were clear improvements in the knowledge of participating students, retained some five months after the course, and indication of other less tangible attitudinal benefits. These findings should encourage further extension of the course to a wider audience and alert the medical profession to the need to pay greater attention to the teaching of the ethical dimensions of human rights. For South African medical professionals, adequate training in medical ethics and human rights is a historical challenge, made all the more urgent by the work of the country's Truth and Reconciliation Commission.

\section{Acknowledgements}

The authors wish to thank Professor Benatar of the Bioethics Centre and Department of Medicine, the Trauma Centre for Victims of Violence and Torture and Warner-Lambert, a pharmaceutical company, for their support in this initiative, and to thank the students of the fourth year class at the University of Cape Town medical school for their enthusiastic participation.

Leslie London, MB ChB, BSc Hons (Epi), DOH, MD, MMed (Comm Health) is Associate Professor in the Department of Community Health, University of Cape Town, Rondebosch. G McCarthy, $M B C h B$, FCPsych (SA) is Principal Specialist, Mental Health Programme, Department of Health, Provincial Administration of the Western Cape, Bellville, South Africa. Correspondence to $L$ London, Associate Professor, Department of Community Health,University of Cape Town Medical School, Private Bag
Rondebosch 7700, South Africa. Fax: +27-2变4066163;Email: ll@anat.uct.ac.za

\section{References}

1 Sorensen B, Vesti P. Medical education for the prevention of torture. Medical Education. 1990;24:467-9.

2 Hannibal K. Taking up the challenge: the promotion of hum rights. A guide for the scientific community. Science and Humin Rights Programme. Washington: American Association $\overline{\mathrm{Dr}}$ Advancement of Science (AAAS), 1992.

3 BMA (British Medical Association). Medicine betrayed. The p pt ticipation of doctors in human rights abuses. London: Zed Publishers, 1992.

4 American College of Physicians. The role of the physician and the medical profession in the prevention of international torture and in the treatment of its survivors. Annals of Inter Medicine 1995;122:607-13.

5 Benatar SR, Jenkins T. Teaching medical ethics in South Afri [editorial]. South African Medical fournal 1988;73:449-52. (D)

6 Rayner M. Turning a blind eye? Medical accountability and prevention of torture in South Africa. Washington: Committee. on Scientific Freedom, American Association for the Advance ment of Science, 1987.

7 Geiger HJ. Health professions and human rights-the long road. Southern African fournal of Public Health [insert]. Sowh African Medical fournal 1997;87:241.

8 Spencer Jones J. Health, truth and reconciliation. (MASA News) South African Medical fournal 1997;87:844-9.

9 London L, Rangaka T, Ratamane S, et al. Medical complicity torture. South African Medical fournal 1996;86:1069-70.

10 Kirsch RE. Doctors and the TRC - confronting our past [edi通rial]. South African Medical fournal 1997;87:711.

11 London L. Bitter pill for doctors. Democracy in Action. $19 \overrightarrow{g g}$ 9(4): 10 .

12 Winslow T. First course on health and human rights. Frture 1995;5(3):61.

13 Abdool Karim SS. Promoting health and human rights: South Africa. Southern African fournal of Public Health [ifer: South African Medical fournal 1997;87:240.

14 London L, McCarthy G, van Heerden J, et al. Preparing fut doctors to meet ethical challenges: a training course for medical students in health and human rights. Southern African fowr nal of Public Health [insert]. South African Medical fourmal 1997;87:242-5.

15 See reference 14: 242-3.

16 Fleiss JL. Statistical methods for rates and proportions [2nd New York: John Wiley, 1981:212-36.

17 Rosner B. Fundamentals of biostatistics [3rd ed]. Boston: PIS Kent, 1990.

18 See reference $14: 243-5$

19 See reference 14:244.

20 Hauser PM. The limitations of KAP surveys. In: Bulmer Warwick DP, eds. Social science in developing countries [1st ed]] New York: John Wiley and Sons, 1983:65-9.

21 See reference 8:844-9.

22 Nightingale EO, Stover E. A question of conscience. Physicians in defense of human rights. Fournal of the American Medioal Association 1986;255:2794-7. 